\title{
Epidemiology and management of splenic injury: An analysis of a Chinese military registry
}

\author{
YONG CHEN, JUN QIU, AO YANG, DANFENG YUAN and JIHONG ZHOU \\ State Key Laboratory of Trauma, Burns and Combined Injury, Department 4, Research Institute of Surgery, \\ Daping Hospital, The Third Military Medical University, Chongqing 400042, P.R. China
}

Received August 15, 2015; Accepted December 23, 2016

DOI: $10.3892 / e t m .2017 .4208$

\begin{abstract}
In China, there have been few meta-analyses of the epidemiology and management of splenic injury. Due to the success of Chinese military hospitals in the domestic treatment of splenic injury, the present study conducted a systematic review of such cases, identifying a high occurrence rate of splenic trauma, as well as a number of strategies of managing splenic injury in China. Data were collected from sixteen Chinese military hospitals between July 2000 and March 2009, and retrospectively reviewed. It was observed that between July 2000 and March 2009 a total of 7,807 patients ( $84.32 \%$ male and $15.68 \%$ female) with splenic injury were admitted to hospital. The mean duration of hospital stay was $17.9 \pm 18.6$ days and the gender distribution of splenic injury over the successive years did not differ significantly $(\mathrm{P}>0.05$, $\mathrm{c}=0.034$ ). However, there was a significant difference in the gender distribution of splenic injury patients in different months $(\mathrm{P}<0.05, \mathrm{c}=0.063)$. In addition, admission numbers for splenic injury were highest in September, October and November. It was also found that splenic injury may occur at all ages, though patients of working age (20-50 years), which comprises $85.59 \%$ of patients, the highest proportion of all recorded cases. Associations between mortality rate and each management strategy were as follows: Operative management, $0.11 \%$ and non-operative management, $0.15 \%$. Furthermore, multivariate analysis demonstrated that transfusion, New Injury Severity Score and management strategies were all correlated with mortality rate. Thus, despite a lack of data for inpatients from civilian hospitals, the present study has, in part, identified the epidemiology and management strategies of splenic injury in China. These findings may supplement those from previous analyses of splenic injury in other countries and regions.
\end{abstract}

Correspondence to: Professor Jihong Zhou, State Key Laboratory of Trauma, Burns and Combined Injury, Department 4, Research Institute of Surgery, Daping Hospital, The Third Military Medical University, 10 Changjiang Zhilu, Chongqing 400042, P.R. China E-mail: zhoujihong2015@163.com

Key words: splenic injury, epidemiology, management, mortality

\section{Introduction}

Trauma is a global healthcare issue and is the fourth most common cause of human mortality after cardiovascular diseases, cancer and chronic respiratory disease (1). Therefore, trauma is responsible for a considerable social economic burden and greatly affects society. Among the abdominal organs, the spleen and liver are most vulnerable to injury (2), with splenic injury typically being caused by a blunt or penetrating injury. As such, splenic trauma can occur at any age. The management of splenic injury has shifted from observational and initial management strategies to the current practices of operative management, including splenorrhaphy, partial splenectomy, splenic artery ligation and splenectomy and non-operative management (NOM), primarily including transfusion and observation (3). Although the use of NOM regarding the treatment of splenic injury has improved, its safety and effectiveness are not well established.

Compared with developed countries, trauma and emergency care system is virtually non-existent in developing or low and middle-income countries (LMICs). Furthermore, $>90 \%$ of injury-related mortality occurs in LMICs (4). China is a densely populated developing country endangered by a high rate of trauma According to Wang et al (5), $10 \%$ of all mortalities and $30 \%$ of all potentially productive life years lost were due to trauma related injuries. Road traffic trauma, suicide, drowning, falls and poisoning were the leading causes of trauma-related mortality in China between 2002 and 2006 (5). Costa et al (6) reported that up to $45 \%$ of patients with blunt abdominal trauma also present with a splenic injury. In order to improve the prognosis of patients with splenic trauma, it is necessary to understand its epidemiology and the different potential management strategies. However, there is a lack of data regarding the epidemiology and management strategies of splenic injury in China. It is established that Chinese military hospitals are experienced in the management of trauma, due to their involvement in natural disaster rescue missions, transportation accidents and trauma research. For instance, trauma experts from military hospitals have aided in a number of domestic rescue missions, such as the 1976 Tangshan and 2008 Wenchuan earthquakes (7).

In the present study, a retrospective analysis of splenic injury admissions in Chinese military hospitals between 
July 2000 and March 2009 was performed, with the aim of identifying the frequency, patterns and management strategies of splenic injury that lead to patient mortality. General epidemiological characteristics and management strategies were also reviewed. The results of the present study may prove useful in the prevention and management of splenic trauma, thus improving patient prognosis.

\section{Materials and methods}

Source of data. Data in the present study was from the 'No. 1 Military Medical Project' information system (8), which was created and promoted by the Medical Department Information Center of the Ministry of General Logistics of the Chinese People of Liberation Army (PLA). The information system, created to manage clinical information and medical economics, contains three main function modules: Patient information management, medical economic management and medical material management. It also includes major hospital management functions and key procedures of clinical practice.

From September 1995, this information system has been used in >200 military hospitals and >100 civil hospitals (8).

Inclusion criteria. The patient data abstracted from the 'No. 1 Military Medical Project' information system between July 2000 and March 2009 included information on standard demographics, New Injury Severity Score (NISS), age, gender, time distribution, transfusion requirements, length of hospital stay (LOS), intensive care unit LOS (ICU LOS), hospitalization expenses and mortality rates. The grade of splenic injury was classified according to the Abbreviated Injury Scoring (AIS) system of the American Association for the Surgery of Trauma (9). Patients were additionally classified according to whether they underwent operative management (OM) or NOM. Cases of splenomegaly, liver cirrhosis and iatrogenic injury were excluded from the current study, as well as patients with splenic injury who underwent splenectomy as part of another procedure without a primary splenic injury or for a splenic artery injury without splenic parenchymal damage. Informed consent was obtained from all participants whose hospital information was included in Chinese Trauma Databank (CTDB). The study, including the consent procedure, was approved by the Ethics Committee of the Third Affiliated Hospital of the Third Military Medical University.

Data analysis. Statistical analyses were performed using SPSS 19.0 software (IBM SPSS, Armonk, NY, USA). For categorical variables, associations between data were analyzed by the $\chi^{2}$ test. As the $\chi^{2}$ value is affected by association strength and sample size, the value may be overrepresented by a large sample size, as in the current study. Therefore, a contingency coefficient was used in order to moderate the statistical significance of results. For continuous variables, the Mann-Whitney U test was applied for the comparison of two groups. A multivariate analysis with a stepwise logistic regression model was also performed, using the patients with splenic injury and their corresponding mortality rates as dependent variables. $\mathrm{P}<0.05$ was considered to indicate a statistically significant difference.

\section{Results}

Patient demographics. Between July 2000 and March 2009, a total of 7,807 patients with splenic injury were admitted to Chinese military hospitals. Of these patients, $84.3 \%(6,398)$ were male and $15.7 \%(1,409)$ were female, and the mean age was $34.4 \pm 13.7$ years. The mortality rate was $0.9 \%(67 / 7807)$.

Gender and age distribution of admissions. The admission of rates of splenic injury victims did not greatly differ from 2001-2008 (Fig. 1). No significant difference was observed between gender distribution of splenic injury incidence from year to year $(\mathrm{P}=0.454, \mathrm{c}=0.034$; Table $\mathrm{I})$, or from months to month $(\mathrm{P}<0.01, \mathrm{c}=0.063$; Table I). Splenic injury admissions were more prevalent in September, October and November than in any other months (Fig. 2). In addition, those of working age (20-50 years) had the highest incidence of splenic injury relative to other age groups: 0-9, 10-19, and 50+ years, accounting for $60.4 \%$ of all recorded admissions (Fig. 3). Gender disparity in age distribution was statistically significant $(\mathrm{P}<0.01, \mathrm{c}=0.090$; Table I). Male patients 30-39 years old accounted for a large number proportion $(29.2 \%)$ of the total number of male victims (Table I).

Distribution of patient study variables based on management strategy. Transfusion rate, age, LOS, ICU LOS, hospitalization cost, NISS, spleen AIS grade and mortality rate were determined according to management strategy (OM or NOM), as depicted in Table II. A total of $48.3 \%$ of spleen injuries grade were IV or V, $32.9 \%$ were I or II, while the remaining $18.8 \%$ were III. The mean age of the study population was $34.4 \pm 13.7$ years and $7.6 \%$ of the population was $>55$ years old. The mean age of patients managed by OM was significantly lower than that of patients managed by NOM (32.3 \pm 13.7 vs. $34.9 \pm 13.8$, respectively; $\mathrm{P}<0.001$ ), while for patients $>55$ years old, the proportion managed by OM was significantly greater than that managed by NOM ( 8.1 vs. $6.0 \%$, respectively; $\mathrm{P}<0.001)$. In addition, relative to patients managed by NOM, those managed by OM had a significantly higher NISS $(\mathrm{P}<0.001)$, likelihood of blood transfusion $(\mathrm{P}<0.001)$ and hospitalization cost $(\mathrm{P}<0.001)$, as well as a significantly longer LOS $(\mathrm{P}<0.001)$ and ICU LOS $(\mathrm{P}<0.001$; Table II $)$.

Predictors of mortality from multivariate analysis. As depicted in Table III, six patient variables were entered into a logistic regression model. Age, ICU LOS and gender were excluded by the model, while management strategy, NISS and transfusion rate were included as independent risk factors of mortality: A total of 67 patients succumbed to their injuries and the management strategy $(\mathrm{P}<0.005)$, transfusion rate $(\mathrm{P}<0.001)$ and NISS $(\mathrm{P}<0.001)$ were observed to be statistically independent variables correlating with the mortality rate of patients. The multivariate analysis of mortality demonstrated that OM and transfusion are protective factors of splenic injury. In addition, patient mortality rate increased as NISS increased.

\section{Discussion}

Trauma is a major cause of mortality, particularly in patients who have undergone abdominal trauma and splenic injury, 
Table I. Gender distribution of splenic injury patients based on age group and admission date.

\begin{tabular}{|c|c|c|c|c|c|}
\hline Variable & Male, n (\%) & Female, n (\%) & $\chi^{2}$ & P-value & $\mathrm{C}$ \\
\hline Year $^{\mathrm{a}}$ & & & 8.824 & $0.454^{*}$ & 0.034 \\
\hline 2000 & $232(3.6)$ & $40(2.8)$ & & & \\
\hline 2001 & $782(12.2)$ & $168(11.9)$ & & & \\
\hline 2002 & 785 (12.2) & $171(12.1)$ & & & \\
\hline 2003 & $799(12.5)$ & $164(11.6)$ & & & \\
\hline 2004 & $767(12)$ & $148(10.5)$ & & & \\
\hline 2005 & 700 (10.9) & $158(11.2)$ & & & \\
\hline 2006 & $774(12.1)$ & $182(12.1)$ & & & \\
\hline 2007 & $770(12)$ & $189(13.4)$ & & & \\
\hline 2008 & $686(10.7)$ & $160(11.4)$ & & & \\
\hline 2009 & $104(1.6)$ & $28(2)$ & & & \\
\hline Month $^{\mathrm{b}}$ & & & 30.721 & 0.001 & 0.063 \\
\hline January & $413(6.5)$ & $125(8.9)$ & & & \\
\hline February & $389(6.1)$ & $90(6.4)$ & & & \\
\hline March & $518(8.1)$ & $92(6.5)$ & & & \\
\hline April & $545(8.5)$ & $122(8.7)$ & & & \\
\hline May & $542(8.5)$ & $137(9.7)$ & & & \\
\hline June & $516(8.1)$ & $119(8.5)$ & & & \\
\hline July & $529(8.3)$ & $124(8.8)$ & & & \\
\hline August & $555(8.7)$ & $120(8.5)$ & & & \\
\hline September & $600(9.4)$ & $154(11)$ & & & \\
\hline October & $653(10.2)$ & $118(8.4)$ & & & \\
\hline November & $631(9.8)$ & $106(7.5)$ & & & \\
\hline December & $508(7.9)$ & $101(7.2)$ & & & \\
\hline Age group, years ${ }^{c}$ & & & 65.211 & $<0.001$ & 0.090 \\
\hline $0-9$ & $145(2.3)$ & $76(5.4)$ & & & \\
\hline $10-19$ & $770(12)$ & $124(8.8)$ & & & \\
\hline $20-29$ & $1496(23.4)$ & $320(22.7)$ & & & \\
\hline $30-39$ & 1867 (29.2) & $399(28.3)$ & & & \\
\hline $40-49$ & $1360(12.2)$ & $264(18.8)$ & & & \\
\hline$>50$ & 761 (11.9) & $215(15.3)$ & & & \\
\hline
\end{tabular}

${ }^{*} \mathrm{P}>0.05$, the difference has no statistical significance. ${ }^{\mathrm{a}}$ Males vs. female distribution from year to year; ${ }^{\mathrm{b}} \mathrm{male}$ vs. female distribution from month to month; ${ }^{c}$ male vs. female distribution in all age groups. P-value estimated by chi-square tests; $c$, contingency coefficient $(\alpha=0.05)$.

for which a mortality rate of $45 \%$ has been documented (10). These patients generally undergo immediate operative or non-operative management, depending on the patients' condition and clinicians' judgment (10). The present study analyzed the data of inpatients admitted to Chinese military hospitals with splenic injury, with the aim of identifying the pattern, incidence and management strategies of splenic trauma. Understanding the epidemiology and management of splenic injury may aid in the prevention of splenic injury and reduce its incidence, fatality and disability rates.

In accordance with a previous study (11), the results of the present study demonstrated that splenic injury occurred most frequently in patients aged between 20-50 years old in which males were more likely to suffer from splenic injury. This may be due to economic pressures of family leading to higher rates of employment within this age group. In addition, compared with other developed countries, the insurance status and socioeconomic standards are less advanced in developing countries $(12,13)$. Therefore, a number of citizens may work in poor working environments, where the risks of abdominal injuries are higher.

The present study demonstrated that there was no significant change in the number of yearly splenic injury admissions between July 2000 and March 2009, the reason for which is unknown, due to the absence of a regional base population. It was also observed that splenic injury incidences peaked in September, October and November, possibly due to the majority of Chinese citizens experiencing workplace pressure to achieve a satisfactory end-of-year bonus during this period.

Management strategies for splenic injury have improved in the last 30 years, however NOM remains controversial (14-16). 
Table II. Distribution of splenic injury patient study variables based on management strategy.

\begin{tabular}{|c|c|c|c|c|}
\hline Variable & OM patients & NOM patients & Total patients & P-value \\
\hline $\mathrm{n}$ & 5786 & 2021 & 7807 & \\
\hline Transfusion (\%) & 69.3 & 3.9 & 54.2 & $<0.001$ \\
\hline Age (mean) & $32.3 \pm 13.7$ & $34.9 \pm 13.8$ & $34.3 \pm 13.8$ & $<0.001$ \\
\hline Age > $55(\%)$ & 8.1 & 6.0 & 7.6 & $<0.001$ \\
\hline $\mathrm{LOS}($ mean $\pm \mathrm{SD})$ & $19.7 \pm 19.9$ & $12.6 \pm 12.8$ & $17.8 \pm 18.6$ & $<0.001$ \\
\hline ICU LOS (mean \pm SD) & $0.6 \pm 2.6$ & $0.2 \pm 1.2$ & $0.5 \pm 2.4$ & $<0.001$ \\
\hline Hospitalization cost $($ mean $\pm \mathrm{SD})$ & $18245.9 \pm 22493.1$ & $5569.9 \pm 7195.9$ & $15097.2 \pm 20495.5$ & $<0.001$ \\
\hline NISS $($ mean \pm SD) & $5.81 \pm 5.21$ & $4.49 \pm 3.91$ & $5.47 \pm 4.94$ & $<0.001$ \\
\hline \multicolumn{5}{|l|}{ Spleen AIS grade $(\%)$} \\
\hline $1 / 2$ & 20.2 & 69.3 & 32.9 & \\
\hline 3 & 19.2 & 17.5 & 18.8 & \\
\hline $4 / 5$ & 60.6 & 13.2 & 48.3 & \\
\hline Mortality (\%) & 1.1 & 0.1 & 0.9 & $<0.001$ \\
\hline
\end{tabular}

OM, operative management; NOM, non-operative management; LOS, length of stay; ICU LOS, intensive care unit length of stay; NISS, New Injury Severity Score; AIS, abbreviated injury scale; SD, standard deviation.

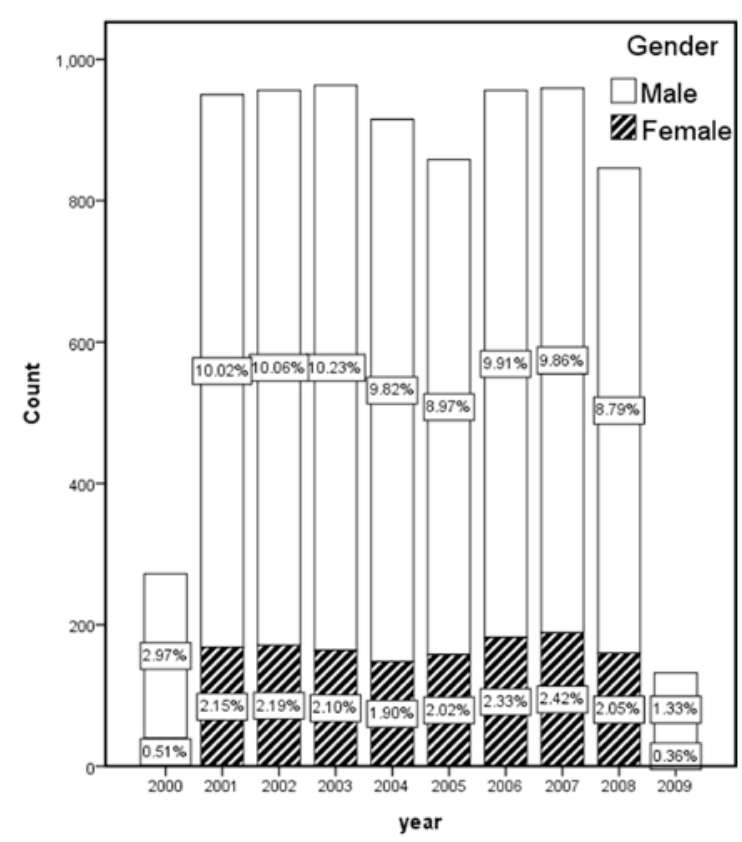

Figure 1. Annual splenic injury admissions to Chinese military hospitals from 2000-2009. The gender distribution of admission rate is presented relative to the total number of splenic injury admissions. No significant difference was observed between the gender distributions of splenic injury incidence from year to year, assessed using a $\chi^{2} . \mathrm{P}=0.426, \mathrm{c}=0.034$.

Stassen et al (17) documented that NOM of blunt splenic injuries is generally suitable for patients with hemodynamic stability, irrespective of injury grade, patient age or the presence of coexisting injuries. However, Frandon et al (18) demonstrated that $55 \%$ of patients with splenic injury experienced $\geq 1$ adverse event during their recovery period, with this rate increasing up to $96 \%$ for those who had undergone OM. However, it was concluded this rate was unrelated to management strategy and more likely due to the severity of injury and presence of coexisting injuries. The present study indicated

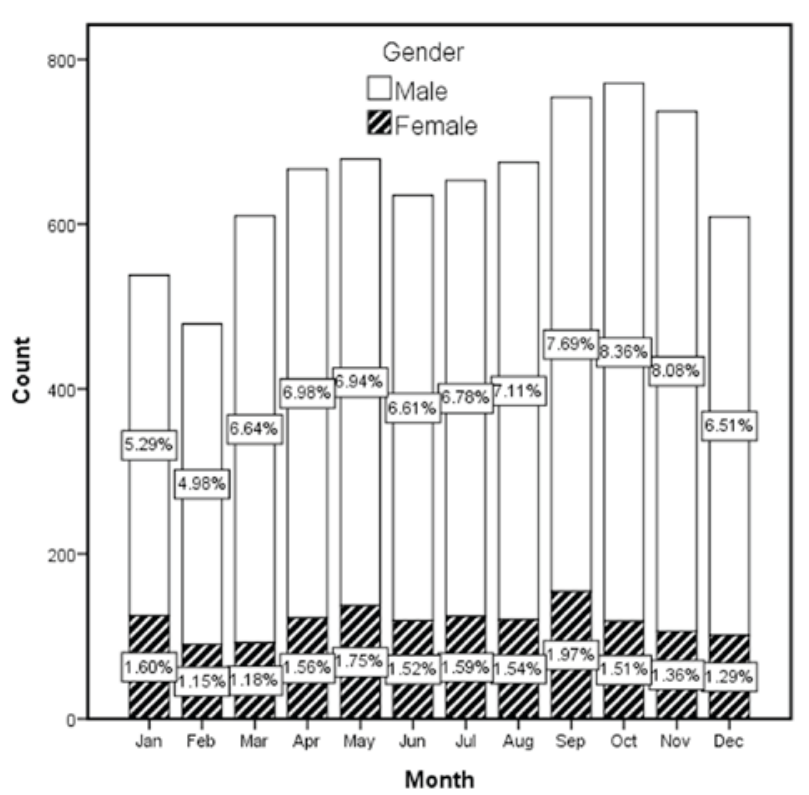

Figure 2. Total monthly admissions of splenic injury to Chinese military hospitals between July 2000 and March 2009. The gender distribution of admission rate is displayed relative to the total number of splenic injury admissions. No significant difference was observed between the gender distributions of splenic injury incidence between months, assessed using a $\chi^{2} . \mathrm{P}<0.01, \mathrm{c}=0.063$. Splenic injury admissions were more prevalent in September, October and November than in any other months.

that patients in the NOM group were significantly older than those in the OM group, and that the LOS, hospitalization cost, spleen AIS grade and NISS of patients in the NOM group were all lower than those in the OM group. Although a number of previous studies suggest that NOM may be suitable for patients with splenic injury with hemodynamic stability $<55$ years (19-21), the present study observed that $8.1 \%$ of patients aged $>55$ with low NISS underwent surgical treatment. These data indicate that the evaluation of the severity 
Table III. Multivariate analysis of mortality rate in splenic injury patients.

$95 \%$ CI per $\operatorname{Exp}(\mathrm{B})$

\begin{tabular}{|c|c|c|c|c|c|c|c|c|}
\hline Variable & $\mathrm{B}$ & S.E & Wals & df & Sig. & $\operatorname{Exp}(B)$ & Lower & Upper \\
\hline \multicolumn{9}{|l|}{ Step $1^{\mathrm{a}}$} \\
\hline Management (OM) & -1.346 & 0.630 & 4.567 & 1 & 0.033 & 0.260 & 0.076 & 0.894 \\
\hline ICU LOS & 0.008 & 0.039 & 0.038 & 1 & 0.845 & 1.008 & 0.934 & 1.087 \\
\hline Transfusion & -1.006 & 0.354 & 8.070 & 1 & 0.004 & 0.366 & 0.183 & 0.732 \\
\hline Age & -0.008 & 0.009 & 0.797 & 1 & 0.372 & 0.992 & 0.974 & 1.010 \\
\hline NISS & 0.042 & 0.010 & 17.622 & 1 & 0.000 & 1.043 & 1.023 & 1.064 \\
\hline Constant & -4.290 & 0.346 & 153.883 & 1 & 0.000 & 0.014 & & \\
\hline \multicolumn{9}{|l|}{ Step $2^{\mathrm{a}}$} \\
\hline Management (OM) & -1.347 & 0.630 & 4.575 & 1 & 0.032 & 0.260 & 0.076 & 0.893 \\
\hline Transfusion & -1.010 & 0.353 & 8.169 & 1 & 0.004 & 0.364 & 0.182 & 0.728 \\
\hline Age & -0.008 & 0.009 & 0.787 & 1 & 0.375 & 0.992 & 0.974 & 1.010 \\
\hline NISS & 0.042 & 0.010 & 17.674 & 1 & 0.000 & 1.043 & 1.023 & 1.064 \\
\hline Constant & -4.285 & 0.345 & 154.347 & 1 & 0.000 & 0.014 & & \\
\hline \multicolumn{9}{|l|}{ Step $3^{\mathrm{a}}$} \\
\hline Management (OM) & -1.341 & 0.630 & 4.537 & 1 & 0.033 & 0.262 & 0.076 & 0.898 \\
\hline Transfusion (transfused) & -.992 & 0.353 & 7.909 & 1 & 0.005 & 0.371 & 0.186 & 0.7490 \\
\hline NISS & 0.041 & 0.010 & 16.978 & 1 & 0.000 & 1.042 & 1.022 & 1.062 \\
\hline Constant & -4.562 & 0.161 & 805.732 & 1 & 0.000 & 0.010 & & \\
\hline
\end{tabular}

B, $\beta$ coefficient; S.E, standard error; Wals, weighted alternating least squares; df, degrees of freedom; Sig, significance; Exp, exponential; CI, confidence interval; OM, operative management; ICU LOS, intensive care unit length of stay; NISS, New Injury Severity Score; ${ }^{a}$ variables entered at step 1: Management, ICU LOS, transfusion, age and NISS.

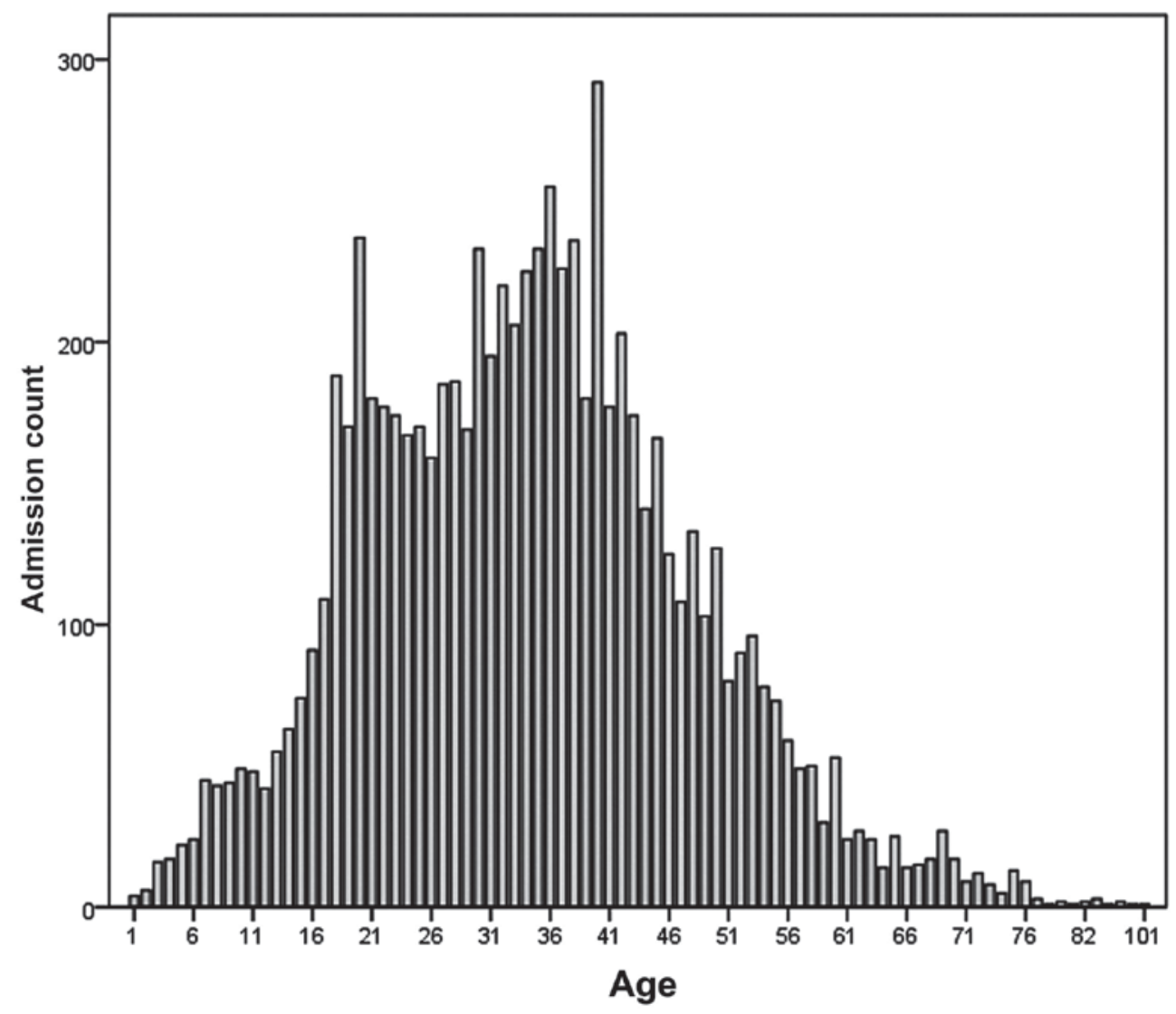

Figure 3. Age distribution of total admission between July 2000 and March 2009. 
of splenic injury, intensive care unit stay, age and transfusion, are necessary prior to initiating NOM.

In a systemic review by Olthof et al (22), ten cohort studies (between 1995 and 2011) were analyzed, in which a total of 25 prognostic factors associated with a high risk of NOM failure were evaluated. It was observed that a patient age of $\geq 40$ years and ISS $>25$ were key prognostic factors of NOM failure. In the present study, age, gender, LOS and ICU LOS were not significantly correlated with mortality rate, while NISS, as a measure of overall trauma severity, was identified as an independent risk factor that was significantly correlated with mortality rate. Previous studies have observed that polytrauma patients have a higher mortality rate than those with an isolated organ injury $(6,23,24)$. Polytrauma patients typically receive a blood transfusion due to the associated risk of exsanguinations, hemorrhage shock and/or low blood pressure; however, Robinson et al (25) determined that blood transfusion is key prognostic marker of mortality in patients with splenic injury. Specifically, after controlling for indices of shock and injury severity, it was demonstrated that those patients receiving blood within the first $24 \mathrm{~h}$ were $\mathrm{x} 4.75$ more likely to succumb to their injuries as those who were not administered a transfusion. In the present study, transfused patients had a higher mortality rate $(83.5 \%)$ relative to non-transfused patients $(16.5 \%)$. The percentage of total patients receiving a blood transfusion was $54.9 \%$, with $69.3 \%$ of these patients receiving surgery. Therefore, patients with splenic injury who underwent transfusion were more likely to have hemodynamic instability and splenic injury of greater severity than non-transfused patients.

The majority of patients that present with splenic injury managed by NOM experience adequate recovery, particularly pediatric patients $(26,27)$. This may be due to the development of artery angiography and embolization, and the increasing use of computed tomography (CT) scanning. Although the use of NOM in managing lower grades of splenic injury remains a topic of debate, NOM is currently the preferred treatment strategy for hemodynamically stable patients. To determine the efficacy of NOM, future studies evaluating patient hemodynamic stability, imaging applications and failures in NOM are warranted.

The present study had several limitations. Data in the 'No. 1 Military Medical Project' information system concerns inpatient information from military hospitals, and is not a specific platform for recording trauma data. Therefore, the aetiology of some patients was incompletely described, including missing information on splenic trauma diagnosis and subsequent operational procedures, leading to a reduced data set. In addition, the information system did not include laboratory or clinical data of patients, including Glasgow Coma Scale scores, hemodynamic values, blood pressure, CT results and injury distribution. Operation times, post operation infections and the failure rate of NOM were also not recorded in the information system, resulting in some loss of data regarding the analysis of management strategies.

In conclusion, the present study evaluated a large sample of patients admitted to Chinese military hospitals with splenic injuries over a $\sim 10$ year period. Analysis of the patient data suggested that there were differences in admission dates, patient ages and factors influencing mortality rate, relative to studies conducted in other countries and regions. The present findings also indicate the epidemiology and management strategies of splenic injury in China, which may aid in improving the prognosis and treatment methods for splenic trauma patients in the future.

\section{Acknowledgements}

The present study was supported by grant from the Twelfth Five Years Project of the PLA (grant no. BWS12J033) and the research special fund for public welfare industry of health (grant no. 201302016).

\section{References}

1. World Health Organization: World Health Statistical 2011. http://www.who.int/gho/publications/world_health_statistics/ EN_WHS2011_Full.pdf. Accessed November 28, 2011.

2. Chiotoroiu AL, Venter DM, Negoi I, Vartosu C, Plotogea O, Paun S, Vartic M and Beuran M: Splenic implant assessment in trauma. Chirurgia (Bucur) 109: 731-740, 2014.

3. Cirocchi R, Corsi A, Castellani E, Chiotoroiu AL, Venter DM, Negoi I, Vartosu C, Plotogea O, Paun S, Vartic M and Beuran M: Case series of non-operative management vs. operative management of splenic injury after blunt trauma. Ulus Travma Acil Cerrahi Derg 20: 91-96, 2014.

4. Sakran JV, Greer SE, Werlin E and McCunn M: Care of the injured worldwide: Trauma still the neglected disease of modern society. Scand J Trauma Resusc Emerg Med 20: 64, 2012.

5. Wang SY, Li YH, Chi GB, Xiao SY, Ozanne-Smith J, Stevenson $M$ and Phillips MR: Injury-related fatalities in China: An under-recognised public-health problem. Lancet 372: 1765-1773, 2008.

6. Costa G, Tierno SM, Tomassini F, Venturini L, Frezza B, Cancrini $G$ and Stella F: The epidemiology and clinical evaluation of abdominal trauma. An analysis of a multidisciplinary trauma registry. Ann Ital Chir 81: 95-102, 2010.

7. Zhang L, Liu X, Li Y, Liu Y, Liu Z, Lin J, Shen J, Tang X, Zhang $\mathrm{Y}$ and Liang W: Emergency medical rescue efforts after a major earthquake: Lessons from the 2008 Wenchuan earthquake. Lancet 379: 853-861, 2012.

8. Xu JH, Qiu J, Zhou JH, Zhang L, Yuan DF, Dai W and Gao ZM: Pediatric burns in military hospitals of China from 2001 to 2007: A retrospective study. Burns 40: 1780-1788, 2014.

9. Moore EE, Cogbill TH, Jurkovich GJ, Shackford SR, Malangoni MA and Champion HR: Organ injury scaling: Spleen and liver (1994 revision). J Trauma 38: 323-324, 1995.

10. Hildebrand DR, Ben-Sassi A, Ross NP, Macvicar R, Frizelle FA and Watson AJ: Modern management of splenic trauma. BMJ 348: g1864, 2014.

11. Soo KM, Lin TY, Chen CW, Lin YK, Kuo LC, Wang JY, Lee WC and Lin HL: More becomes less: Management strategy has definitely changed over the past decade of splenic injury-a nationwide population-based study. Biomed Res Int 2015: 124969, 2015.

12. Hazlitt M, Hill JB, Gunter OL and Guillamondegui OD: Disparities in trauma: The impact of socioeconomic factors on outcomes following traumatic hollow viscus injury. J Surg Res 191: 6-11, 2014

13. Greene WR, Oyetunji TA, Bowers U, Haider AH, Mellman TA, Cornwell EE, Siram SM and Chang DC: Insurance status is a potent predictor of outcomes in both blunt and penetrating trauma. Am J Surg 199: 554-557, 2010.

14. Singer DB: Postsplenectomy sepsis. Perspect Pediatr Pathol 1: 285-311, 1973

15. Davies DA, Pearl RH, Ein SH, Langer JC and Wales PW: Management of blunt splenic injury in children: Evolution of the non-operative approach. J Pediatr Surg 44: 1005-1008, 2009.

16. Hoskins W, Jacob A, Wijeratne S, Campbell I and Taylor P: Splenic injury admitted to a rural Level 3 trauma centre: A 10-year audit. Aust J Rural Health 21: 163-169, 2013. 
17. Stassen NA, Bhullar I, Cheng JD, Crandall ML, Friese RS, Guillamondegui OD, Jawa RS, Maung AA, Rohs TJ Jr, Sangosanya A, et al: Selective nonoperative management of blunt splenic injury: An Eastern Association for the Surgery of Trauma practice management guideline. J Trauma Acute Care Surg 73: S294-S300, 2012.

18. Frandon J, Rodiere M, Arvieux C, Vendrell A, Boussat B, Sengel C, Broux C, Bricault I, Ferretti G and Thony F: Blunt splenic injury: Are early adverse events related to trauma, nonoperative management, or surgery? Diagn Interv Radiol 21: 327-333, 2015.

19. Cirocchi R, Boselli C, Corsi A, Farinella E, Listorti C, Trastulli S Renzi C, Desiderio J, Santoro A, Cagini L, et al: Is non-operative management safe and effective for all splenic blunt trauma? A systematic review. Crit Care 17: R185, 2013.

20. Cocanour CS: Blunt splenic injury. Curr Opin Crit Care 16: $575-581,2010$.

21. Watson GA, Hoffman MK and Peitzman AB: Nonoperative management of blunt splenic injury: What is new? Eur J Trauma Emerg Surg 41: 219-228, 2015.

22. Olthof DC, Joosse P, van der Vlies $\mathrm{CH}$, de Haan RJ and Goslings JC: Prognostic factors for failure of nonoperative management in adults with blunt splenic injury: A systematic review. J Trauma Acute Care Surg 74: 546-557, 2013.
23. Rostas J, Cason B, Simmons J, Frotan MA, Brevard SB and Gonzalez RP: The validity of abdominal examination in blunt trauma patients with distracting injuries. J Trauma Acute Care Surg 78: 1095-1101, 2015.

24. Peitzman AB: Focus on blunt abdominal trauma. Eur J Trauma Emerg Surg 41: 217, 2015.

25. Robinson WP III, Ahn J, Stiffler A, Rutherford EJ, Hurd H, Zarzaur BL, Baker CC, Meyer AA and Rich PB: Blood transfusion is an independent predictor of increased mortality in nonoperatively managed blunt hepatic and splenic injuries. J Trauma 58: 437-445, 2005.

26. Aubrey-Bassler FK and Sowers N: 613 cases of splenic rupture without risk factors or previously diagnosed disease: A systematic review. BMC Emerg Med 12: 11, 2012.

27. Duron VP, Day KM, Steigman SA, Aidlen JT and Luks FI: Maintaining low transfusion and angioembolization rates in the age of nonoperative management of pediatric blunt splenic injury. Am Surg 80: 1159-1163, 2014. 